\title{
Teaching Writing through Genre-based Approach
}

\author{
Luu Trong Tuan \\ Ho Chi Minh City University of Finance-Marketing, Vietnam \\ Email: luutrongtuan@vnn.vn
}

\begin{abstract}
This research is an endeavour to examine the impact of genre-based approach on students' writing performance as well as students' attitudes towards the implementation of genre-based approach in writing learning. Research findings reveal that most of the students gained the control over the key features of the required recount genre in terms of social purposes, language features and schematic structure. The necessity and usefulness of the application of teaching-learning cycle into learning the recount genre was predominantly recognized among students.
\end{abstract}

Index Terms - genre-based approach, teaching writing, EFL

\section{INTRODUCTION}

Writing skill is deemed to be difficult for EFL students in the language learning (Richards, 1990). According to Richard and Renandya (2002), the difficulties include those in (1) generating and organizing ideas using an appropriate choice of vocabulary, sentence and paragraph organization and (2) putting such ideas into an intelligible text. As for Vietnamese EFL students, besides these difficulties, they also have to face many other obstacles when learning to write compositions in English.

The first difficulty rests in the fact that English in Vietnamese universities nowadays is treated primarily as a compulsory subject for studying and for exam-driven purposes rather than as a tool for communication. Students have been asked to do the multiple choice tests on their final exams which include several sections on grammar, vocabulary, reading comprehension and writing. In the writing section, students are asked to "rewrite" some sentences in another way but keep exactly the same meaning as the given ones. They are also asked to repair word order in jumbled-word sentences or fill in the blanks with the suitable verbs or verbal phrases. As passing exams is vital for students' lives, most of the time in class, a large number of teachers may be in more favor of teaching such writing skills to help their students pass the exams.

Secondly, the "so-called" teaching writing approach of composition deployed by teachers at present may expose some difficulties for students in the performance of the compositional writing skills. In terms of teaching English compositions, most of the teachers just focus on providing their student writers with vocabulary relating to the required topic and some guiding questions in order to help them shape their ideas into the completed paragraphs. Teaching writing in this way only benefits them to an extent that it can assist them in producing the error-free texts following the models of correct language. However, it does not contribute to help students realize and master such features as purposes, audiences, context and linguistic conventions of text which are the important features of any text-types.

In other words, writing classes in university nowadays are still predominantly language-based writing classes that focus on sentence writing for exam-orientation rather than focus on writing-based classes that focus on creating compositions in order to serve for the purposes of plurality of real readers outside the classroom context.

This research is an endeavour to seek for ways that can both enhance students' writing skills and build up their positive perceptions towards learning this skill. The genre-based approach chosen in this research is to solve students' difficulties in learning to write English compositions. This research is guided by the ensuing questions:

1. To what extent can students' academic recount essays actually be improved with respect to social purposes, schematic structure and language features after their exposure to genre-based approach?

2. What are students' attitudes towards the use of the genre-based approach in learning to write?

\section{LITERATURE REVIEW}

\section{A. What is Genre?}

"Genre" refers not only to types of literary texts but also to the predictable and recurring patterns of everyday, academic and literary texts occurring within a particular culture (Hammond and Derewianka, 2001). In the western countries, "genre" or "text-type", either spoken or written, is often identified/grouped according to its primary social purposes. According to Swale (1990), the genres which share the same purposes belong to the same text-types. Derewianka (1990) identified further six main school type-types according to their primary social purposes: (1) Narratives: tell a story, usually to entertain; (2) Recount: To tell what happened; (3) Information reports: provide factual information; (4) Instruction: tell the listeners or readers what to do; (5) Explanation: Explain why or how something happens; (6) Expository texts: Present or argue a viewpoint. These social purposes of the text-genres in turn decide the linguistic inputs of the text (i.e. their linguistic conventions, often in form of schematic structure and linguistic features). Specifically, schematic structure refers 
to internal structure or text organization of the text-type in forms of introduction, body and conclusion while language features consist of linguistic aspects such as grammar, vocabulary, connectors and etc the writers have to use in order to translate information/ideas into a readable text.

\section{B. Genre-based Approach}

A genre-based approach placed great emphasis on the relationship between text-genres and their contexts (Hyon, 1996). In doing so, it aimed to help students become effective participants in their academic and professional environment as well as in their broader communities (Hammond and Derewianka, 2001). Following are some characteristics of the genre-based approach.

First, the genre-based approach emphasizes the importance of exploring the social and cultural context of language use on a piece of writing. The context decides the purpose of a text, an overall structure of a text in terms of language features and text features often in the form of linguistic conventions (Hammond and Derewianka, 2001; Hyon, 1996). This approach argues that students can only produce a composition to be successfully accepted by a particular English-language discourse community once they take context of a text into account into their own writing papers.

Second, this approach highlights the magnitude of the readers and the linguistic conventions that a piece of writing needs to follow in order to be successfully accepted by its readership (Muncie, 2002). According to this approach, any student who wants to be successful in joining a particular English-language discourse community, he or she will need to be able to produce texts which fulfill the expectations of its readers in regards to grammar, organization, and content.

Third, it underscores that writing is a social activity. This notion originated from the social-cultural theory initiated by Vygotsky (1978). According to this theory, knowledge is best constructed when learners collaborate together, support one another to encourage new ways to form, construct and reflect on new knowledge. In this case, social interactions and participation of group members play a key role in developing new knowledge. In the writing classes, students are encouraged to participate in the activities of meaning exchange and negotiation with their more capable people such as peers and teacher. Learning writing in this way, as it is believed, can remove the feeling of isolation which bothers many learners when writing and at the same time, help student writers have positive reinforcements about the knowledge of linguistics, content and ideas in the composing of texts.

Fourth, a genre-based approach to writing instruction looks beyond subject content, composing processes and linguistic forms to see a text as attempts to communicate with readers. This approach is concerned with teaching learners how to use language patterns to accomplish coherent, purposeful prose writing. Its central belief is that "we do not just to write, we write something to achieve some purpose" (Hyland, 2003, p. 18). In this approach, student writers are requested to consider the overall social purposes of a text into account when composing a text.

Fifth, this approach emphasizes the important role of writer-reader interaction on a piece of writing (Reid, 1995). Firstly, student writer in this approach is requested to specify or think about the intended and/or potential readers when writing in order to be able to select or anticipate appropriate content, language and levels of formality. He or she should always ask himself or herself some questions such as who will be my intended readers?, who might be interested in reading my text?, what are their beliefs about a good piece of writing?, what are their levels of English proficiency? and what are their educational and cultural backgrounds?, etc. Similarly, readers when approaching the text should also ask themselves some questions such as for what purposes does this writer write this piece of writing?, what is the writer's viewpoint when writing the text?, what kinds of language features and organization does he/she use in the text?, and etc. To recap, there always exist an interaction between writer and its readers in the form of written communication despite the absence of readers.

Sixth, teacher's role in this approach is viewed as authoritativeness rather than authoritarian (Rothery, 1996). As an expert in the classroom, the teacher provides students with systematic guidance and careful support through various activities so that students ultimately gain the control of written genres. At the same time, he/she also recognizes the importance of students' contributions to the teaching-learning process.

Last but not least, the genre-based approach emphasizes the explicit teaching of the linguistic conventions of the genre for L2 novice student writers (Christie, 1990). It is argued that students cannot produce a particular text-type successfully if they are not taught explicitly about linguistic conventions of that text-type with respect to language features and schematic structure. Therefore, making known these conventions to student writers; especially at the first stage of the instructional modules of particular text-types is a very important task of genre-based teachers. In the classroom, teacher following genre orientation often employs the teaching-learning cycle which comprises the three phases, namely, modeling of a "sample expert" text, joint-negotiation of text with teacher, and independent construction of text by individual student (Cope and Kalantzis, 1993).

\section{METHODOLOGY}

\section{A. Participants}

Forty five first-year students of Class 010C from Ho Chi Minh City University of Finance-Marketing were invited to take part in an experimental writing class in which the researcher used the genre pedagogy's teaching-learning cycle in order to teach the student participants to write on biographical recount genre. This extra curricular writing activity was conducted outside their regular-class hours between February 2011 and May 2011 in order to offer the student participants 
a lot of opportunities to practice more in the writing skills. Meanwhile, the four skills are still regarded as the key elements in the mainstream English coursebooks in the regular-class hours at school.

\section{B. Data Collection and Analysis}

Research data was collated through student essays and questionnaire for students.

Student essays

The essays collected were the ones written on the following topic "Write about a famous person". the analysis of these essays were based on the three evaluative criteria of the recount genres developed and explained by Droga and Humphrey (2003). More specifically, the students' text analysis focused on:

- Students' control over the social purposes of the required recount genre: to give accounts of the most important events in the life of a specific character in history (for biographical recount genre).

- Students' control over the schematic structure of the recount genre. These include: The orientation phase, the sequence of events in chronological order phase and the re-orientation phase.

- Students' control over the language features of the recount genre. These include: focus on the main specific human participants, process types (i.e. material process, relational process and mental process), circumstantial adverbs of time, and the past tenses of verbs.

Questionnaire for students

A Vietnamese version of questionnaire consisting of two parts, part A and part B, which was designed to elicit students' attitudes towards the genre pedagogy's teaching-learning cycle and the recount genre was administered to forty five firstyear students right after they had finished the instructional module of the recount genre. This questionnaire composed of closeended questions which were designed on five agreement extensions, namely, strongly agree, agree, uncertain, disagree and strongly disagree as proposed in Likert's work which was published in the late 1920s.

This questionnaire sought to gather information about students' attitudes towards (1) the three phases of teachinglearning cycle and (2) the recount genre. It consisted of 33 items which were distributed in two parts in the form of closeended questions (A, B). Part A with 26 items aimed at the three key phases of teaching-learning cycle and part B with seven items aimed at the recount genre.

\section{DATA ANALYSIS AND DISCUSSIONS}

\section{A. Analysis of Students' Biographical Recount Essays}

TABLE 1.

STUDENTS' CONTROLS OVER THE KEY FEATURES OF THE BIOGRAPHICAL RECOUNT ESSAYS

\begin{tabular}{|c|c|c|c|c|c|c|c|c|}
\hline \multirow[b]{2}{*}{ Essays } & \multirow[b]{2}{*}{$\begin{array}{l}\text { Social } \\
\text { purposes }\end{array}$} & \multicolumn{3}{|c|}{$\underline{\text { Schematic structure }}$} & \multicolumn{4}{|c|}{ Language features } \\
\hline & & Orientation & $\begin{array}{l}\text { Sequences } \\
\text { of events }\end{array}$ & Re-orientation & $\begin{array}{l}\text { Main } \\
\text { participants }\end{array}$ & $\begin{array}{l}\text { Process } \\
\text { types }\end{array}$ & $\begin{array}{l}\text { Past tense } \\
\text { of verbs }\end{array}$ & $\begin{array}{l}\text { Circumstantial } \\
\text { adverbs of time }\end{array}$ \\
\hline $\begin{array}{l}\text { No. } \\
\%\end{array}$ & $\begin{array}{l}45 \\
100 \\
\end{array}$ & $\begin{array}{l}45 \\
100 \\
\end{array}$ & $\begin{array}{l}42 \\
93.33 \\
\end{array}$ & $\begin{array}{l}38 \\
84.44\end{array}$ & $\begin{array}{l}45 \\
100 \\
\end{array}$ & $\begin{array}{l}45 \\
100 \\
\end{array}$ & $\begin{array}{l}45 \\
100 \\
\end{array}$ & $\begin{array}{l}45 \\
100 \\
\end{array}$ \\
\hline
\end{tabular}

Table 1 indicates that more than $80 \%$ of the students were successful in gaining controls over the key features of the biographical recount essays.

With respect to the schematic structure, most student participants demonstrated all typical phases of a biographical recount essay, namely, an orientation, a sequence of events and a reorientation. Specifically, in the orientation, they identified a famous person as the main participant and then provided the reasons for his fame in their orientation. Thus, they succeeded in revealing the social purpose of their essays: To give an account of a famous specific character in the history. In the same vein, in the sequences of event phases, they demonstrated their good understanding and good execution of typical features of a biographical recount genre by unfolding the major phases in the famous person's life in a temporal order, deploying proper circumstantial adverbs of time and proper tenses of verbs, and finally rounded off their essays by summarizing the famous person's contributions to the society.

Moreover, they were also successful in deploying proper linguistic resources of the biographical recount genre by focusing on one main participant, using a variety of process types such as Material process, Relational Process, Mental Process across the schematic structure of their essays, using proper past tenses of verbs and circumstantial adverbs of time. Interestingly, they also know how to use the other adverb elements such as cause, place, result, purpose and concession to make their whole essays hang together.

In a nutshell, it was evident from their essays that majority of the students gained control over the features of the biographical recount genre.

\section{B. Analysis of Students' Attitudes towards the Teaching-learning Cycle and the Recount Genre}

Students' attitudes towards the teaching-learning cycle

This section displays the three themes which are the modeling of the recount genre, joint-construction of the recount genre and independent construction of the recount genre respectively. 
- Phase 1: Modeling of the recount genre

This phase is subdivided into two subphases: context exploration and text exploration.

* Context exploration

TABLE 2 .

STUDENTS' ATTITUDES TOWARDS THE ACTIVITIES IN THE CONTEXT EXPLORATION OF THE RECOUNT GENRE

\begin{tabular}{|c|c|c|c|c|c|c|}
\hline $\begin{array}{l}\text { The activities in the } \\
\text { context exploration }\end{array}$ & $\begin{array}{l}\text { SA } \\
5\end{array}$ & $\begin{array}{l}\text { A } \\
4\end{array}$ & $\begin{array}{l}\mathrm{U} \\
3\end{array}$ & $\begin{array}{l}\mathrm{D} \\
2\end{array}$ & $\begin{array}{l}\text { SD } \\
1\end{array}$ & $\begin{array}{l}\mathrm{M} \\
3.0\end{array}$ \\
\hline 1. Realizing the social purposes of the recount genre. & $\begin{array}{l}20 \\
44.4\end{array}$ & $\begin{array}{l}20 \\
44.4\end{array}$ & $\begin{array}{l}5 \\
11.1\end{array}$ & $\begin{array}{l}0 \\
0.0\end{array}$ & $\begin{array}{l}0 \\
0.0\end{array}$ & 4.3 \\
\hline 2. Knowing the writer of the recount genre. & $\begin{array}{l}17 \\
37.8 \\
\end{array}$ & $\begin{array}{l}23 \\
51.1\end{array}$ & $\begin{array}{l}5 \\
11.1\end{array}$ & $\begin{array}{l}0 \\
0.0\end{array}$ & $\begin{array}{l}0 \\
0.0\end{array}$ & 4.3 \\
\hline 3. Knowing the intended readers of the recount genre. & $\begin{array}{l}17 \\
37.8 \\
\end{array}$ & $\begin{array}{l}23 \\
51.1 \\
\end{array}$ & $\begin{array}{l}5 \\
11.1 \\
\end{array}$ & $\begin{array}{l}0 \\
0.0 \\
\end{array}$ & $\begin{array}{l}0 \\
0.0 \\
\end{array}$ & 4.3 \\
\hline 4. Exploring the possible contexts of situation of the recount genre. & $\begin{array}{l}9 \\
20.0 \\
\end{array}$ & $\begin{array}{l}25 \\
55.6 \\
\end{array}$ & $\begin{array}{l}9 \\
20.0 \\
\end{array}$ & $\begin{array}{l}2 \\
4.4 \\
\end{array}$ & $\begin{array}{l}0 \\
0.0 \\
\end{array}$ & 3.9 \\
\hline 5. Realizing that the contextual factors can affect the production of the recount genre. & $\begin{array}{l}12 \\
26.7\end{array}$ & $\begin{array}{l}15 \\
33.3\end{array}$ & $\begin{array}{l}15 \\
33.3\end{array}$ & $\begin{array}{l}2 \\
4.4\end{array}$ & $\begin{array}{l}1 \\
2.2\end{array}$ & 3.8 \\
\hline 6. Activating their background knowledge. & $\begin{array}{l}15 \\
33.3\end{array}$ & $\begin{array}{l}25 \\
55.6\end{array}$ & $\begin{array}{l}5 \\
11.1\end{array}$ & $\begin{array}{l}0 \\
0.0\end{array}$ & $\begin{array}{l}0 \\
0.0\end{array}$ & 4.2 \\
\hline 7. Expressing their personal opinions or attitudes towards the recount genre. & $\begin{array}{l}12 \\
26.7\end{array}$ & $\begin{array}{l}15 \\
33.3\end{array}$ & $\begin{array}{l}15 \\
33.3\end{array}$ & $\begin{array}{l}2 \\
4.4\end{array}$ & $\begin{array}{l}1 \\
2.2\end{array}$ & 3.8 \\
\hline 8. Necessity and usefulness for them in the latter phases of learning writing. & $\begin{array}{l}27 \\
60.0 \\
\end{array}$ & $\begin{array}{l}14 \\
31.1 \\
\end{array}$ & $\begin{array}{l}4 \\
8.9 \\
\end{array}$ & $\begin{array}{l}0 \\
0.0 \\
\end{array}$ & $\begin{array}{l}0 \\
0.0 \\
\end{array}$ & 4.5 \\
\hline
\end{tabular}

$\mathrm{SA}=$ Strongly agree, $\mathrm{A}=$ Agree, $\mathrm{U}=$ Uncertain, $\mathrm{D}=$ Disagree, $\mathrm{SD}=$ Strongly disagree

As indicated in Table 2, the majority of student participants $(91.1 \%)$ reckoned that the activities in the context exploration was necessary and useful for them in the latter phases of learning writing $(M=4.5)$. Concretely, 27 students accounting for $60 \%$ agreed that these activities really helped them in learning writing in addition to 14 students (31.1\%) expressing their strong agreement towards this statement. As a result, most of the students expressed their positive opinions from approval to strong approval (M ranged from 3.8 to 4.3) to the 7 remaining items (from item 1 to item 7) with respect to realizing the purposes of the recount genre, knowing the reasons why writer writes the recount genre, the audiences of the recount genre, knowing the situations where the recount genre can be applied, helping explore the contextual factors affecting the production of the recount genre, helping activate their background knowledge and expressing their personal opinions towards the recount genre. Specifically, around $88.8 \%$ of the respondents affirmed that the activities in the context exploration could help them realize the social purposes, writer and the intended readers of the recount genre. In the same vein, nearly the same number $88 \%$ of them noted that these activities helped them realize in what situation this genre could be applied and roughly $90 \%$ of the respondents showed that these activities could activate their prior knowledge towards the recount genre. Although the criteria in terms of exploring the possible contexts of situation of the recount genre and expressing their personal opinions towards the recount genre were not warmly received with favorable opinions (i.e. the hesitation of the respondents dropped from high proportion $33.3 \%$ to low proportion $20 \%$ ), $77.6 \%$ of them also expressed that these activities were really helpful for them. Finally, roughly $60 \%$ of the respondents, albeit still predominant, reckoned that these activities could help them realize that the contextual factors could affect the production of the recount genre and that these activities were the good chances for them to express their likes and dislikes towards the recount topics which they were learning.

In short, the students' attitudes towards the activities in the first subphase of the modeling of the recount genre were generally positive. Although there were some students showing their uncertainty and disagreement towards some options in the items in this subphase, they were just a few. Generally, all the activities in this subphase actually facilitated and prepared them in the following phases of the teaching-learning cycle.

* Text exploration 
TABLE 3

STUDENTS' ATTITUDES TOWARDS THE ACTIVITIES IN THE TEXT EXPLORATION OF THE RECOUNT GENRE

\begin{tabular}{|c|c|c|c|c|c|c|}
\hline $\begin{array}{l}\text { The activities in } \\
\text { Student choice } \\
\text { the text exploration }\end{array}$ & $\begin{array}{l}\text { SA } \\
5\end{array}$ & $\begin{array}{l}\text { A } \\
4\end{array}$ & $\begin{array}{l}U \\
3\end{array}$ & $\begin{array}{l}\mathrm{D} \\
2\end{array}$ & $\begin{array}{l}\text { SD } \\
1\end{array}$ & $\begin{array}{l}\mathrm{M} \\
3.0\end{array}$ \\
\hline $\begin{array}{l}\text { 1. Realizing how the information is structured in the sample recount genre to reach the } \\
\text { purposes, audiences, content and text organization. }\end{array}$ & $\begin{array}{l}21 \\
46.7\end{array}$ & $\begin{array}{ll}19 \\
42.2\end{array}$ & $\begin{array}{ll}5 \\
11.1\end{array}$ & $\begin{array}{ll}0 \\
0.0\end{array}$ & $\begin{array}{l}0 \\
0.0\end{array}$ & 4.4 \\
\hline $\begin{array}{l}\text { 2. Picking up the salient language features of the recount genre thanks to the teacher's } \\
\text { explicit analysis of these features. }\end{array}$ & $\begin{array}{l}27 \\
60.0 \\
\end{array}$ & $\begin{array}{l}13 \\
28.9\end{array}$ & $\begin{array}{l}5 \\
11.1\end{array}$ & $\begin{array}{l}0 \\
0.0\end{array}$ & $\begin{array}{l}0 \\
0.0\end{array}$ & 4.5 \\
\hline $\begin{array}{l}\text { 3. Picking up the salient schematic structure of the recount genre thanks to the teacher's } \\
\text { explicit analysis of these features. }\end{array}$ & $\begin{array}{l}27 \\
60.0\end{array}$ & $\begin{array}{l}13 \\
28.9\end{array}$ & $\begin{array}{l}5 \\
11.1\end{array}$ & $\begin{array}{l}0 \\
0.0\end{array}$ & $\begin{array}{l}0 \\
0.0\end{array}$ & 4.5 \\
\hline 4. Realizing that each recount genre has different writing conventional rules. & $\begin{array}{l}30 \\
66.7\end{array}$ & $\begin{array}{l}10 \\
22.2\end{array}$ & $\begin{array}{l}5 \\
11.1\end{array}$ & $\begin{array}{ll}0 \\
0.0\end{array}$ & $\begin{array}{l}0 \\
0.0\end{array}$ & 4.6 \\
\hline 5. Realizing that these conventional rules of writing differ from culture to culture. & $\begin{array}{l}22 \\
48.9\end{array}$ & $\begin{array}{ll}10 \\
22.2\end{array}$ & $\begin{array}{l}9 \\
20.0\end{array}$ & $\begin{array}{l}4 \\
0.9\end{array}$ & $\begin{array}{ll}0 \\
0.0\end{array}$ & 4.2 \\
\hline $\begin{array}{l}\text { 6. Realizing that conforming to the conventional rules of a particular recount genre is very } \\
\text { important when writing. }\end{array}$ & $\begin{array}{l}30 \\
66.7\end{array}$ & $\begin{array}{ll}10 \\
22.2\end{array}$ & $\begin{array}{ll}5 \\
11.0\end{array}$ & $\begin{array}{ll}0 \\
0.0\end{array}$ & $\begin{array}{ll}0 \\
0.0\end{array}$ & 4.6 \\
\hline 7. Necessity and usefulness for them in the latter phases of learning writing. & $\begin{array}{l}25 \\
55.6\end{array}$ & $\begin{array}{ll}15 \\
33.3\end{array}$ & $\begin{array}{ll}5 \\
11.1\end{array}$ & $\begin{array}{ll}0 \\
0.0\end{array}$ & $\begin{array}{ll}0 \\
0.0\end{array}$ & 4.4 \\
\hline
\end{tabular}

It is obvious from Table 3 that the activities in the text exploration of the recount genre could facilitate students in learning writing in particular and in the latter phases of their learning writing in general. Indeed, $88.9 \%$ of them expressed their approval towards these activities with $55.6 \%$ higher percentage of strong agreement and lower percentage $33.3 \%$ of agreement. In turn, their strong belief entailed their agreement to the 6 remaining items (from item 1 to item 6). In addition, it was also noted that only 5 students each asked expressed their uncertainty in the items 1, 2, 3, 4, 6 and 9/45 students expressed their hesitation in item 5 along with $4 / 45$ students expressing their disagreement. This indicated that almost all respondents expressed their positive opinions towards the activities in the text exploration. Specifically, $88.9 \%$ of these students expressed that, with the sample text offered and analyzed by the researcher, they could realize how the information was structured to obtain social purposes, language features and schematic structure of the required text. This entailed $27 / 45$ students $(60 \%)$, together with $13 / 45$ students $(28.9 \%)$ expressing their agreement, strongly agreed that they were able to pick up the salient language features and schematic structure which were suitable for the required recount genre thanks to the process the researcher analyzed the features of the required sample recounts for them. Interestingly, $88.9 \%$ of the respondents, which was albeit $88.9 \%$ of the respondents in the item 7 , reported that, in their viewpoints, conforming to the linguistic conventions of a particular recount genre was very important for them to learn writing (88.9\%) Finally, it was found in item 5 that $32 / 45$ students $(71.1 \%)$ agreed that the conventional rules of writing differed from cultures to cultures.

To sum up, the text exploration subphase was really useful and necessary for students in learning writing. This was confirmed in their positive responses towards the aspects of the social purposes, language features, schematic structure and etc. of the required recount genre. This was in coincidence with the researcher's expectations. As identified in the conceptual framework of the teaching-learning cycle, the first phase - modeling - aims at providing the novice students with the "tools" to construct the text with in terms of social purposes, language features and schematic structure of a particular text-type because in this phase students themselves are still unfamiliar with these conventional rules. It turned out that after being taught with this first phase of the cycle, almost all students (88.9\%) expressed their positive feelings towards it. Similarly to the context exploration, it was found in this subphase that some of the students still expressed their doubtfulness and even their disagreement towards this subphase. Nevertheless, the negative reactions from the respondents were very small. On the whole, they acknowledged that this subphase facilitated them in learning writing.

- Phase 2: The joint-construction of the recount genre

TABLE 4

STUDENTS' ATTITUDES TOWARDS THE ACTIVITIES IN THE JOINT-CONSTRUCTION OF THE RECOUNT GENRE

\begin{tabular}{|c|c|c|c|c|c|c|}
\hline $\begin{array}{l}\text { The activities in the } \\
\text { joint-construction }\end{array}$ & $\begin{array}{l}\text { SA } \\
5\end{array}$ & $\begin{array}{l}\text { A } \\
4\end{array}$ & $\begin{array}{l}\mathrm{U} \\
3\end{array}$ & $\begin{array}{l}\mathrm{D} \\
2\end{array}$ & $\begin{array}{l}\text { SD } \\
1\end{array}$ & $\begin{array}{l}\text { M } \\
3.0\end{array}$ \\
\hline 1. Applying the theories of the recount genre into practice. & $\begin{array}{l}21 \\
46.7\end{array}$ & $\begin{array}{l}18 \\
40.0\end{array}$ & $\begin{array}{l}4 \\
8.9\end{array}$ & $\begin{array}{l}2 \\
4.4\end{array}$ & $\begin{array}{l}0 \\
0.0\end{array}$ & 4.3 \\
\hline $\begin{array}{l}\text { 2. Realizing that the preparatory phases are very important and necessary for constructing an } \\
\text { effective recount genre. }\end{array}$ & $\begin{array}{l}32 \\
71.1 \\
\end{array}$ & $\begin{array}{l}13 \\
28.9 \\
\end{array}$ & $\begin{array}{l}0 \\
0.0\end{array}$ & $\begin{array}{l}0 \\
0.0 \\
\end{array}$ & $\begin{array}{l}0 \\
0.0 \\
\end{array}$ & 4.7 \\
\hline $\begin{array}{l}\text { 3. Knowing "what to write" in order to achieve the social purposes, language features and } \\
\text { schematic structure of a particular recount genre thanks to the process teacher demonstrates the } \\
\text { way of writing for them. }\end{array}$ & $\begin{array}{l}31 \\
68.9\end{array}$ & $\begin{array}{l}10 \\
20.0\end{array}$ & $\begin{array}{l}1 \\
2.2\end{array}$ & $\begin{array}{l}3 \\
6.7\end{array}$ & $\begin{array}{l}0 \\
0.0\end{array}$ & 4.5 \\
\hline $\begin{array}{l}\text { 4. Knowing "how to write" in order to achieve the social purposes, language features and } \\
\text { schematic structure of a particular recount genre thanks to the process teacher demonstrates the } \\
\text { way of writing for them. }\end{array}$ & $\begin{array}{l}31 \\
68.9\end{array}$ & $\begin{array}{l}10 \\
20.0\end{array}$ & $\begin{array}{l}1 \\
2.2\end{array}$ & $\begin{array}{l}3 \\
6.7\end{array}$ & $\begin{array}{l}0 \\
0.0\end{array}$ & 4.5 \\
\hline 5. Necessity and usefulness for them in the latter phase of learning writing. & $\begin{array}{l}23 \\
51.1 \\
\end{array}$ & $\begin{array}{l}17 \\
37.8 \\
\end{array}$ & $\begin{array}{l}5 \\
11.1 \\
\end{array}$ & $\begin{array}{l}0 \\
0.0 \\
\end{array}$ & $\begin{array}{l}0 \\
0.0 \\
\end{array}$ & 4.4 \\
\hline
\end{tabular}


Table 4 shows that roughly $90 \%$ of the student respondents thought that the activities in the joint-construction phase were necessary and useful for them in learning writing $(M=4.4)$. This was confirmed by the fact that nearly all of the respondents were of the opinion from agreement to strong agreement with (M ranged from 4.3 to 4.7, items 1-4 in Table 4). In particular, $86.7 \%$ of them expressed that they knew how to apply the theories of the recount genre in terms of orientation, sequences of events in chronological order and reorientation into practice. The figure $8.9 \%$ of uncertainty and $2 \%$ of disagreement in this statement did not indicate the big differences in terms of negative attitudes in this item. More interestingly, the preparatory phases such as researching information from many sources (e.g. from internet, textbooks, newspapers, teachers and peers) earned the most favorable opinions ( $71.1 \%$ strongly agree and $28.9 \%$ agree). Finally, roughly $90 \%$ of the student respondents agreed that they knew "what and how to write" in each phase to achieve the social purposes, language features and schematic structure of a required recount genre in the independent construction phase of the recount genre thanks to the process their teacher demonstrated the way of writing for them.

Briefly speaking, this phase was generally really helpful for students in learning writing. It was served as a transitional subphase of the first phase in transforming the theories they picked up into practice. This phase was successfully implemented thanks to the collaborative writing processes between teacher and students with teacher acting as a scribe. Although this phase was also received with unfavorable responses from the respondents like phase "modeling", these negative reactions were just a few. On the whole, all of these activities were considered to be very necessary before the student writers were asked to write independently.

- Phase 3: The independent construction of the recount genre

TABLE 5.

STUDENTS' ATTITUDES TOWARDS THE ACTIVITIES IN THE INDEPENDENT CONSTRUCTION

\begin{tabular}{|c|c|c|c|c|c|c|}
\hline $\begin{array}{l}\text { The teaching writing } \\
\text { Student choice } \\
\text { techniques applied in the } \\
\text { Independent construction }\end{array}$ & $\begin{array}{l}\text { SA } \\
5\end{array}$ & $\begin{array}{l}\text { A } \\
4\end{array}$ & $\begin{array}{l}\mathrm{U} \\
3\end{array}$ & $\begin{array}{l}\mathrm{D} \\
2\end{array}$ & $\begin{array}{l}\text { SD } \\
1\end{array}$ & $\begin{array}{l}\mathrm{M} \\
3.0\end{array}$ \\
\hline 1. Writing many drafts can help improve their own essays. & $\begin{array}{ll}31 \\
68.9\end{array}$ & $\begin{array}{l}10 \\
20.0\end{array}$ & $\begin{array}{ll}1 \\
2.2\end{array}$ & $\begin{array}{l}3 \\
6.7\end{array}$ & $\begin{array}{l}0 \\
0.0\end{array}$ & 4.5 \\
\hline 2. The constructive feedbacks of their friends towards their first drafts better their second drafts. & $\begin{array}{l}21 \\
46.7\end{array}$ & $\begin{array}{l}18 \\
40.0\end{array}$ & $\begin{array}{l}4 \\
8.9\end{array}$ & $\begin{array}{l}1 \\
2.2\end{array}$ & $\begin{array}{ll}0 \\
0.0\end{array}$ & 4.2 \\
\hline $\begin{array}{l}\text { 3. Their feedbacks towards their friends' drafts can help them review the knowledge of the recount } \\
\text { genre and realize their mistakes (if possible) in their own recount essays. }\end{array}$ & $\begin{array}{l}25 \\
55.6\end{array}$ & $\begin{array}{l}12 \\
26.7\end{array}$ & $\begin{array}{l}6 \\
13.3 \\
\end{array}$ & $\begin{array}{l}1 \\
2.2\end{array}$ & $\begin{array}{l}1 \\
2.2\end{array}$ & 5.1 \\
\hline $\begin{array}{l}\text { 4. Teacher's feedbacks can help them realize whether their recount essays fulfilled the contents of the } \\
\text { required recount genre or not. }\end{array}$ & $\begin{array}{l}30 \\
66.7\end{array}$ & $\begin{array}{ll}15 \\
33.3\end{array}$ & $\begin{array}{ll}0 \\
0.0\end{array}$ & $\begin{array}{lll}0 \\
0.0\end{array}$ & $\begin{array}{ll}0 \\
0.0\end{array}$ & 4.7 \\
\hline $\begin{array}{l}\text { 5. Their final recount essays are much better improved after being given feedbacks and corrections by } \\
\text { their friends and teacher. }\end{array}$ & $\begin{array}{l}18 \\
40.0\end{array}$ & $\begin{array}{l}21 \\
46.7\end{array}$ & $\begin{array}{l}6 \\
13.3\end{array}$ & $\begin{array}{l}0 \\
0.0\end{array}$ & $\begin{array}{l}0 \\
0.0\end{array}$ & 4.3 \\
\hline 6. These teaching writing techniques are necessary and useful for learning to write any text-types. & $\begin{array}{l}18 \\
40.0\end{array}$ & $\begin{array}{l}22 \\
48.9\end{array}$ & $\begin{array}{l}5 \\
11.1\end{array}$ & $\begin{array}{l}0 \\
0.0\end{array}$ & $\begin{array}{l}0 \\
0.0\end{array}$ & 4.3 \\
\hline
\end{tabular}

It is clear from Table 5 that the teaching writing techniques applied in the phase "independent construction of the recount" were really helpful for students (roughly 90\%). From the Table 5, it was seen that most of the students responded positively to the issues of writing many drafts, peer feedback and teacher's feedback (M ranged from 4.2 to 5.1). In terms of writing many drafts, roughly $90 \%$ of the respondents expressed that it did really help them improve their writing skills. As for their friends' feedback, 21 out of 18 students in the scale agreement extension strongly agreed that this activity could help them improve their second drafts $(86.7 \%)$. That meant that in giving constructive feedbacks of their friends towards their first drafts, their friends could help them locate as well as point out to them the mistakes or errors committed in their first drafts and at the same time suggested the ways of helping them revise their first drafts to become better. Also, they agreed that their feedbacks towards their friends' drafts could help them review the knowledge of the recount and spotted their mistakes and errors in their own papers (82.3\%). More importantly, teacher's feedbacks received the most favorable opinions (100\%) in which $66.7 \%$ expressed their total agreement along with $33.3 \%$ of agreement. As such, they were of the opinion that their final written products were better improved after being offered the constructive feedbacks and corrections from their friends and teacher (86.7\%). Like phases 1 and 2 above, besides the positive responses offered by students, the researcher still received a relatively small percentage of other respondents who both expressed their uncertainty and their rejection towards the usefulness of these teaching writing strategies used in the cycle which needed paying more attention to.

In brief, the last phase of the teaching-learning cycle did contribute to the learning of writing of students in this study. This was expressed in the high proportion of percentage of agreements towards the teaching writing techniques used by the researcher. Certainly, the positive responses of students were not by chance. The statistical figures actually indicated these positive attitudes.

Students' attitudes towards the recount genre 
TABLE 6

STUDENTS' ATTITUDES TOWARDS THE RECOUNT GENRE

\begin{tabular}{|l|l|l|l|l|l|l|}
\hline \multicolumn{1}{|c|}{ Student choice } & SA & A & U & D & SD & M \\
The recount genre & 5 & 4 & 3 & 2 & 1 & 3.0 \\
\hline 1. Suitability for their learning English at university. & 17 & 28 & 0 & 0 & 0 & \\
& 37.8 & 62.2 & 0.0 & 0.0 & 0.0 & 4.4 \\
\hline 2. Suitability for their learning English in the near future. & 12 & 22 & 11 & 1 & 0 & \\
& 26.7 & 48.9 & 24.4 & 2.2 & 0.0 & 4.0 \\
\hline 3. Suitability and interest for them personally. & 12 & 18 & 13 & 2 & 0 & \\
& 26.7 & 40.0 & 28.9 & 4.4 & 0.0 & 3.7 \\
\hline 4. Suitability for their current English level. & 20 & 20 & 5 & 0 & 0 & \\
& 44.4 & 44.4 & 11.1 & 0.0 & 0.0 & 4.3 \\
\hline 5. Suitability for their age. & 21 & 17 & 5 & 2 & 0 & \\
& 46.7 & 37.8 & 11.1 & 4.4 & 0.0 & 4.3 \\
\hline 6. The biographical recount genre stimulates them to learn to write. & 5 & 10 & 24 & 5 & 1 & \\
& 11.1 & 22.2 & 53.3 & 11.1 & 2.2 & 3.3 \\
\hline
\end{tabular}

From Table 6, it was seen that all respondents agreed that the recount genre chosen for this study was suitable for their learning English at university (17 students agreed and 28 students strongly agreed). However, the following criteria regarding items 2-5 were not received with completely favorable opinions from the respondents although the positive responses in these items were found to be outnumbered than the negative responses. First of all, in terms of suitability for their learning English in the near future, there were 34 students expressing their positive feelings towards it (i.e. 12 students strongly agreed and 22 students agreed) while 11 of them expressed their uncertainty and the other one student rejected this criteria. Secondly, in the next item (suitability and interest for them personally), while 30 out of 45 respondents responded positively towards it (i.e. 12 strongly agreed and 18 agreed), 13 of them expressed their hesitation and the other two students expressed their disagreement towards it. Thirdly, despite the fact that there were 40 respondents agreeing about suitability for their current English level, 5 of them also expressed their doubtfulness towards it. Finally, with respect to suitability for their age, 38 out of 45 respondents expressed their approval while 5 expressed their doubtfulness and 2 expressed their disagreement towards it. These pointed out that there were fluctuations in the attitudes of the respondents ranging from strong agreement, agreement, uncertainty to disagreement towards the suitability and interest of the recount genre.

Finally, in reference to item 6 (i.e. whether they thought the biographical recount genre could stimulate them to learn writing or not), it was seen that there were only 15 students expressing their positive feelings towards the biographical recount genre (i.e. 5/45 expressing their strong agreement and 10 expressing their agreement) while the number of respondents which responded uncertainly and negatively to this genre was very big (i.e. 24/45 respondents expressing their uncertainty plus 6/45 students expressing their disagreement towards this genre: 5 rejection and 1 complete rejection). This indicated that the biographical recount genre chosen for teaching writing in this study did not meet the great expectations from most of the student participants.

All in all, students' attitudes towards the recount genre enjoyed both positive and negative reactions from the respondents, of which positive attitudes were outnumbered than negative attitudes. Apart/except from the criterion (suitability for their learning English at university), other remaining criteria (from item 2 to item 6) were not met with the great expectations from the researcher, especially in terms of stimulating them to learn to write the biographical recount and suitability for their learning English in the future.

\section{CONCLUDING THOUGHTS}

Research findings demonstrate that a genre-based approach based on the three phases of the teaching-learning cycle had created a great impact on these student participants. Indeed, most of the student participants gained control over the key features of the required recount genre and at the same time, expressed their positive feelings towards this cycle as well as the recount genre applied in this study. Although there were still some of the student participants who expressed their disapproval towards some activities carried out in each phase of the teaching-learning cycle and the recount genre, it was found that these negative reactions from these small number of participants did not affect much to the results of the research.

In order to implement successfully this teaching-learning cycle of the genre-based program into their own actual classroom, teachers of English should introduce many well-written sample reading texts which contain the features of the specific text-types into their own classroom. As identified at the outset of this study, one of the difficulties facing the EFL students when they learnt writing skills was that they lacked the knowledge of the text-type in terms of language features and text features; therefore, they did not know how to turn their ideas into their intelligible text. A sample "expert" and "selective" recount genre helped his students realize its purposes, its language features and its schematic structure and they could use this knowledge to produce their similarly own recount genre effectively.

Moreover, the flexibility of the genre-based approach teachers should be also summoned. In other words, they should not be too rigid in applying the three phases into their classroom. For more capable students who understand very clearly the modeling phase and want to practice more of writing skills, teachers can ignore their role as scribes. Instead, he or she should revise and correct their texts which approximate to the structure of the sample text. However, for those students 
who have not yet mastered the structure of the sample reading text, the role of teacher as a scribe in the joint-negotiation phase is still considered necessary.

\section{REFERENCES}

[1] Christie, F. (1990). Genre as Social Processes. A plenary Paper Delivered at the Meanjin Reading Council Regional Conference, Brisbane (March, 23-25), PP. 74-78.

[2] Cope, B., and Kalantzis, M. (1993). Introduction: How a Genre Approach to Literacy can Transform the Way Writing is Taught. In B. Cope \& M. Kalantzis (Eds.), The Powers of Literacy: A genre approach to teaching writing. London: Falmer Press, pp. 1-21.

[3] Derewianka, B. (1990). Exploring How Text Works. Sydney: Primary English Teaching Association.

[4] Droga, L., and Humphrey, S. (2003). Grammar and Meaning: An Introduction for Primary Teachers. Berry News South Wales: Target Text, p. 11.

[5] Hammond, J., and Derewianka, B. (2001). Genre. In R. Carter \& D. Nunan (Eds). The Cambridge Guide to Teaching English to Speakers of Other Languages. Cambridge: Cambridge University Press.

[6] Hyland, K. (2002). Teaching and researching writing. Harlow, Essex: Longman

[7] Hyon, S. (1996). Genre in Three Traditions: Implications for ESL. TESOL Quarterly, Vol. 30, pp. 693-732.

[8] Muncie, J. (2002). Finding a Place for Grammar in EFL Composition Classes. EFL Journal, 56, p. 407-430.

[9] Reid, J. (1995). Teaching ESL Writing. Upper Saddle River, NJ: Heinle and Heinle.

[10] Richards, J.C. (1990). The Language Teaching Matrix. Cambridge: Cambridge University Press.

[11] Richards, J., \& Renandya, W. (2002). Methodology in Language Teaching: An Anthology of Current Practice. Cambridge: Cambridge University press.

[12] Rothery, J. (1996). Making changes: Developing an educational linguistics. In R. Hasan \& G. Williams (Eds.), Literacy in Society. London: Longman.

[13] Swales, J.M. (1990). Genre Analysis- English in Academic Research Settings. Cambridge: Cambridge University Press.

[14] Vygotsky, L.S. (1978). Mind in Society: The Development of Higher Psychological Process. Cambridge, Mass: Havard University Press.

Luu Trong Tuan is currently an EFL teacher at Ho Chi Minh City University for Natural Resources and Environment. He received his M.TESOL from Victoria University, Australia in 2004. Besides his focus on TESOL, his recent publications such as Language Transfer is Cultural Transfer between Communities, Social Sciences Review, No. 11, 2004, pp. 60-63; and Principles for Scientific Translation, Social Sciences Review, No. 8, 2004, pp. 63-67; and Building Vietnamese Medical Terminology via Language Contact, Australian Journal of Linguistics, Vol. 29, No. 3, September 2009, pp. 315-336 show his interest in language contact and translation areas. 